\title{
4. What do we mean when we speak about the effectiveness of governance systems?
}

\section{THE PROBLEM OF EFFECTIVENESS}

A prominent strand of thinking about international or global governance systems and about environmental governance systems in particular asserts that these systems typically perform poorly and sometimes fail altogether. Gus Speth, a former administrator of the UN Development Programme, says that "efforts to protect the global environment have largely failed" and that "more of the same will not get us where we want to be in time to head off an era of unprecedented environmental decline" (Speth 2004, xi). Jacob Park and his colleagues argue that "there has been an enormous vesting of intellectual energy and political capital in efforts to build issue-specific interstate agreements - despite precious little evidence of their effectiveness" (Park et al. 2008, 8). Ken Conca, who directs attention specifically to the role of the United Nations in addressing largescale needs for governance, says that "we also find a UN record of failure, inaction, and disappointment. The fabric of international environmental law, though not entirely threadbare, contains many tears and missing strands" (Conca 2015, 3). And Thomas Hale, David Held, and Kevin Young, focusing on international governance more generally, describe what they call "a 'governance gap' in which crucial needs go unmet" (Hale et al. 2013, 3).

Skepticism of this sort is certainly understandable. The regimes created in the 1990s to address the issues of climate change and the loss of biological diversity have failed to prevent the onset of climate change or to stem mounting losses of biodiversity. The governance system for trade that crosses national boundaries, which seemed robust as recently as the 1990s, is now in tatters. The nuclear nonproliferation regime has not stopped additional states from obtaining nuclear weapons or initiated a phaseout of such weapons on the part of existing nuclear powers. Although international wars of the traditional sort are now uncommon, largescale domestic violence occurs frequently, and outsiders intervene regularly in such situations in a forceful manner without 
seeking authorization from the United Nations. Armed interventions in the former Yugoslavia and in Syria are particularly prominent cases in point. Nor are great powers shy about deploying military force to bring about desired changes in the domestic systems of smaller countries. The American intervention in Iraq and the Russian intervention in Ukraine in the absence of authorization from the United Nations illustrate this class of cases. No wonder, then, that the skeptics ask whether institutions really matter at the international or global level and whether, in the final analysis, we are operating in a world in which outcomes are determined largely by the ability of individual actors to exercise power in one form or another.

Still, it is by no means clear that this is the whole story regarding the effectiveness of governance of world affairs (Young 1999). In this chapter, I take a step back to ask what we mean when we speak about the effectiveness of social institutions operating beyond the level of individual states. In responding to this question, I distinguish among what I will call constitutive, issue-specific, and positional effectiveness. This move makes it clear right away that success in solving specific problems like the looming threat of climate change constitutes only one dimension of what is at stake when we speak about the effectiveness of international or global institutions. Institutions may produce significant consequences in terms of one dimension of effectiveness, even while they perform poorly or fail outright with respect to other dimensions. Particularly important in this connection is the distinction between effectiveness understood as solving problems and effectiveness construed as making a difference in the realm of world affairs.

Adopting this broader perspective, I argue that international or global institutions are often quite effective. In efforts to deal with specific concerns like the impacts of climate change, existing institutions may emerge as part of the problem rather than serving as a basis for crafting solutions. But this is surely not the same thing as asserting that institutions are ineffective or do not matter. We may not like the results that institutions produce, especially when they lock us into arrangements that impede our efforts to address increasingly urgent problems. This phenomenon is by no means peculiar to the realm of world affairs. Those concerned with domestic problems like the impacts of systemic racism or extreme inequality are just as frustrated by the difficulty in overcoming institutionalized biases as those seeking to address global problems like the onset of climate change. The challenge in such cases is to break the grip of entrenched institutions, without at the same time triggering a broader or more general breakdown of social order. 
The literature on international regimes that took root during the 1970s and has become an influential stream of work in the field of international relations is largely issue-specific in the sense that it directs attention to efforts to come to terms with more or less well-defined problems like avoiding severe depletions of fish stocks, combatting transboundary air pollution, halting the spread of nuclear weapons, or preventing battles over jurisdictional claims in Antarctica (Krasner 1983). Those who have produced this literature have taken the question of effectiveness seriously. For example, they have introduced an important distinction among outputs, outcomes, and impacts, where outputs involve creating the arrangements needed to administer regimes, outcomes have to do with the extent to which regimes influence the behavior of subjects, and impacts then become a matter of the extent to which regimes solve or alleviate the problems that led to their creation (Miles et al. 2002; Underdal and Young 2004). They have also exhibited a healthy regard for the difficulties involved in establishing causal connections between the creation of regimes and the occurrence of outcomes and impacts (Young 2011). It is one thing to say that there is a causal connection between the negotiation of an agreement and the establishment of the administrative apparatus required to move its provisions from paper to practice. It is far more complicated to show that the operation of a regime caused changes in the behavior of subjects or produced a solution to the problem. We are increasingly conscious of the role of complex causality in which institutions constitute one of a number of driving forces; we know that sorting out the relative importance of individual drivers is a challenging task.

These are significant achievements in our efforts to understand the effectiveness of institutions. But they do not exhaust the conceptual issues associated with the question of whether, how and to what extent institutions make a difference. Another important dimension of effectiveness encompasses what I call constitutive effectiveness. A helpful, though not entirely precise, way to think about this form of effectiveness is to say that constitutive institutions identify the players, assign roles to them, and lay down the general rules of the game governing the social practices in which they engage. But they do not determine the content of the specific issues addressed by the participants in these practices or the character of the regimes that participants create to deal with these issues. The Charter of the United Nations, for example, is constitutive in this sense. It starts with a general statement of purposes and principles and then proceeds to spell out criteria regarding membership in the United Nations, to establish the principal organs of the body, to clarify the respective roles of these organs, to specify decision rules for each of the organs, and to spell out procedures for amending the Charter. But the Charter does not 
say anything regarding the treatment of substantive issues like the spread of nuclear weapons, the regulation of international trade, or the prevention of climate change. When we describe the UN Framework Convention on Climate Change and the Convention on Biological Diversity as UN conventions, what we mean is that they conform to the constitutive provisions set forth in the Charter. Thus, the members of these conventions are states; interactions among them reflect procedures developed by the UN and disputes regarding provisions of these conventions may be referred to the International Court of Justice if the parties are unable to settle them by other means.

Effectiveness, on this account, is a matter of the extent to which a constitutive arrangement is successful in structuring interactions among its members as they engage in efforts to address specific issues or problems. An arrangement like the Charter of the United Nations may be highly effective in constitutive terms, whether or not regimes established to address specific problems are successful in solving those problems. In some cases, constitutive effectiveness may emerge as part of the problem rather than part of the solution in efforts to address specific problems. Constitutive arrangements are often sticky in the sense that they are resistant to change in the face of all but the most extreme pressures. To the extent that emerging conditions differ more or less drastically from conditions prevailing at the time a constitutive arrangement was created, features of the arrangement may become impediments to problem-solving. The guarantee regarding domestic jurisdiction articulated in Article 2(7) of the Charter, for example, is regarded by many as a barrier to the development of innovative measures to address a range of issues pertaining to human rights and environmental protection. The language of the article makes it clear that the guarantee cannot block or stymie actions under the provisions of Chapter VII dealing with threats to the peace, breaches of the peace, and acts of aggression. This reflects the principal concerns of those drafting the language of the Charter at the close of World War II. But the provisions of Article 2(7) do constitute a significant impediment to efforts to address problems like climate change that have risen to the top of the planetary agenda today. Nevertheless, it is hard to envision practical ways to adjust the language of the Charter at this stage in response to this limitation.

There is a third conception of effectiveness that deserves separate treatment in this discussion. It encompasses what I call positional effectiveness and centers on the determination of who gets what at the international or global level. Just as domestic institutions (e.g., systems of property rights) are compatible with conditions featuring more or less extreme inequality among individual citizens and may even serve to entrench such conditions, international institutions (e.g., systems of sovereign rights) are compatible with extreme inequality among the members of international society and constitute a barrier to some approaches to dealing with this matter. For example, there is no pro- 
vision under existing international institutions dealing with fairness or justice in the distribution of wealth or with the responsibility of wealthy members of international society to make a good faith effort to assist with the development of poorer members. In this sense, institutions matter whether or not we like the consequences they produce. Somewhat similar comments are in order regarding more specific issues that are positional in nature. Under the law of the sea as it stands today, for example, coastal states have rights to exploit the resources of sizable chunks of the world ocean, while non-coastal states have no rights to these marine resources. Outer space, by contrast, is open to use by all members of international society. But it is important to note that only those who have access to advanced technologies are in a position to take advantage of this right. The point is that institutions can and do make a difference in positional terms, whether or not they are a help or a hindrance when it comes to addressing specific problems like the spread of nuclear weapons, the protection of human rights, or the avoidance of severe depletions of stocks of renewable resources.

Two additional conceptual issues deserve consideration before we move on to more substantive matters. The first concerns what a number of authors have taken to calling architectures of global governance (Biermann and Kim 2020). Analysts interested in regimes realized some time ago that there are many cases in which two or more distinct institutional arrangements have grown up to deal with interrelated issues, like plant genetic resources, endangered species, transboundary air pollution, or climate change (Raustiala and Victor 2004; Keohane and Victor 2009). In cases where individual elements interact more or less significantly but are not related to one another in hierarchical terms, researchers have taken to describing the resultant situations as regime complexes or governance complexes (Gomez-Mera et al. 2020). There is now a lively discussion among those who work in this field about mechanisms for the management of regime complexes and the prospects that intergovernmental organizations of one sort or another can play constructive roles in orchestrating situations of this kind to alleviate tensions or encourage the growth of synergy among the elements of regime complexes (Abbott et al. 2020; Stokke 2020).

Proceeding to the next level, some analysts have noted that there are sometimes interactions among regime complexes or what they treat as international networks. Thus, Biermann and Kim define a governance architecture "as the overarching system of public and private institutions, principles, norms, regulations, decision-making procedures and organizations that are valid or active in a given area of global governance" (Biermann and Kim 2020: 4) As they put it, architecture refers to the macro level of governance. Whether the concept of architecture defined in this way proves to be an important contribution to the literature on global or Earth system governance remains to be seen. But what I want to emphasize here is the distinction between architectures and what 
I have described as constitutive institutions. The idea of architecture seeks to draw together regimes, regime complexes, intergovernmental organizations, transnational networks, and various types of nonstate actors in the interests of developing an integrated understanding of how institutions work in broad issue domains. But architectures, on this account, may or may not be constitutive as I have used the term in my description of constitutive institutions. In fact, much of the discussion of architectures appears to assume that constitutive issues are dealt with outside the scope of these institutional structures.

The second conceptual issue has to do with the issue of institutional fragmentation (Biermann et al. 2020). While the term crops up often in recent discussions of international governance, analysts have used the term to refer to a number of phenomena. So, it is important to be careful in commenting on assertions about fragmentation. Still, we can be clear about one major issue. Within a single constitutive system, those dealing with needs for governance can and generally do devise substantive regimes or governance systems to address a variety of specific issues. In domestic systems, for example, legislatures operating within the framework of a single constitutional system create regimes or governance arrangements dealing with health care, education, civil rights, commerce, employment, property, taxation, publicly owned land, environmental protection, and so forth. Of course, tensions at the interfaces between or among these regimes arise from time to time, and governments turn to administrative or legal procedures to address these tensions. It is possible to describe the resultant landscape of governance systems as fragmented in the sense that there is no higher order or synoptic structure available to fit all the pieces of the puzzle together coherently. But it is not clear that this observation adds anything important to our understanding of the nature of governance systems. Much the same can be said of governance systems operating at the international or global level. For example, there are hundreds of multilateral agreements setting up regimes pertaining to environmental matters alone. The same observation can be made about regimes located within other issue domains. All these arrangements operate within the overarching constitutive framework of international society, as articulated in the Charter of the United Nations and other authoritative sources. The result can be described as fragmented in one sense of that term. Certainly, this is not a trivial matter. Nevertheless, situations of this kind constitute a fact of life when it comes to understanding the world of governance systems in all human societies. That is, fragmentation in this sense is a reality that needs to be recognized and dealt with properly rather than a defect that we may be able to eliminate or overcome with sufficient effort. 
From the perspective of governance, the most significant constitutive arrangements operating at the Earth system level center on the institutions that define the planetary system as a society of states in which membership is reserved exclusively for social entities that qualify as states, and the operation of the principle of sovereignty ensures that states have a right to handle their domestic affairs without interference on the part of outsiders coupled with a right to refuse to acknowledge or accept international obligations in the absence of their explicit consent. Of course, compliance with these provisions is not perfect. Powerful states sometimes intervene directly in the internal affairs of weak states and often exert pressure on them to accept obligations they would otherwise reject. As numerous observers have noted, a variety of nonstate actors have worked hard to acquire significant roles in this social environment and succeeded in acquiring real influence in some realms. Nonetheless, the constitutive effectiveness of the institutions that define international society as a states system is undeniable.

Whether the results are desirable or undesirable is another matter. There is growing evidence that some of the grand challenges of governance in the 21st century identified in Chapter 2 (e.g., preventing the eruption of pandemics or controlling misuses of cyberspace) will prove difficult - perhaps impossible - to deal with effectively in an institutional setting dominated by sovereign states. But this tells us nothing about the constitutive effectiveness of the prevailing system or, in other words, the extent to which it makes a difference with respect to the treatment of needs for governance. For better or worse, we can expect to operate for some time in an institutional setting in which efforts to address needs for governance typically involve the negotiation of international legally binding instruments among groups of sovereign states.

Given the constitutive effectiveness of the states system, it is surprising how recently this institutional arrangement has achieved dominance on a global scale. We are used to dating this development from the 1648 Treaty of Westphalia ending the Thirty Years War. But even in Europe, it makes little sense to speak of a fully fledged society of states prior to the unification of Germany and Italy in the second half of the 19th century and quite possibly prior to the dissolution of the Austro-Hungarian and Russian empires in the aftermath of World War I. As to the rest of the world, the spread of the states system is a product of the 20th century and, in many cases, of the period following the close of World War II. The British and French empires, Japanese control of sizable parts of Asia, and the international concessions in China are all difficult to square with the idea of international society as a society of sovereign states. The spread of the states system to encompass all the terrestrial 
portions of the Earth system owes a great deal to the success of the drive to promote decolonization during the course of the decades following World War II. It would be a mistake to exaggerate the role that the United Nations played in this process. Still, it is worth noting that the Charter of the United Nations envisions a global system and that it is based squarely on the idea that international society is and should be organized as a society of states.

All this suggests that international society is not static and that it is not naive to think about alternatives to the states system or at least the development of constitutive arrangements in which nonstate actors achieve recognition as legitimate rights holders in the not-too-distant future. It is not easy to forecast how constitutive changes will occur and exactly where such changes will lead at the global level. For some time, we have looked primarily to processes of economic globalization with its emphasis on the proposition that multinational corporations operating global supply chains that states find difficult or impossible to control will become serious rivals to states in the competition for constitutive legitimacy at the global level. At this stage, doubts about the persuasiveness of this line of thinking are growing. But other developments have emerged to challenge the dominance of the states system going forward. The onset of the cyber age and the growing importance of virtual systems, in particular, are threatening the dominance of states (Young, Yang, and Guttman 2020). A range of nonstate actors (including technologically sophisticated individuals) are able to make use of virtual systems to pursue their objectives in ways that states are unable to control effectively. The rise of technologies that enable various forms of cyber manipulation, cyberterrorism, and cyberwarfare is producing a world in which we can no longer take for granted the dominance of states when it comes to addressing major needs for governance. While this tells us little about what lies ahead, it does raise questions about the effectiveness of the constitutive institutions of the states system.

The constitutive institutions of the states system apply in a straightforward manner only to the terrestrial portions of the Earth system. Since marine systems cover more than two-thirds $(70+\%)$ of the surface of the Earth, this is an important limitation. States are major players when it comes to the governance of ocean spaces. But the constitutive provisions of the law of the sea differ in a number of respects from the constitutive provisions applying to terrestrial spaces. What is more, the law of the sea has evolved steadily in the period since the close of World War II; important developments relating to the law of the sea are in progress at this time. The ongoing effort to devise institutional arrangements dealing with biodiversity in areas beyond national jurisdiction is particularly significant. In constitutive terms, it is reasonable to expect that the governance system applicable to marine spaces will look substantially different in 2050 than it looked in 1950. 
The cornerstone of the prevailing law of the sea is the 1982 UN Convention on the Law of the Sea (UNCLOS) that entered into force in 1994. Although there is room for debate about some of the provisions of UNCLOS, large parts of the convention are constitutive in nature in the sense that they provide a general framework within which a variety of substantive regimes operate (Oude Elferink 2005). Thus, regimes dealing with marine mammals (e.g., the International Convention for the Regulation of Whaling), commercial shipping (e.g., SOLAS and MARPOL), commercial fishing (e.g., a variety of regional fisheries management organizations), and environmental protection (e.g., OSPAR) are all nested within the constitutive provisions of the law of the sea. In some respects, UNCLOS is properly understood as a part of the general operating system of international society. The convention is a treaty negotiated under the auspices of the United Nations; the members of the convention are sovereign states; the provisions of the convention have the status of international law. Nevertheless, UNCLOS sets forth a constitutive system that differs in important respects from the constitutive system applicable to terrestrial spaces.

To begin with, UNCLOS draws a clear distinction between coastal states and members of international society that have no borders adjacent to marine spaces. Coastal states are accorded jurisdiction with varying degrees of control over what are known as their internal waters, territorial seas, and Exclusive Economic Zones (EEZ). In all cases, this control is more limited than the control states are authorized to exercise over their terrestrial spaces. For example, coastal states must respect the right of vessels registered in other states to engage in innocent passage through their territorial seas and EEZs and transit passage through international straits under their jurisdiction. Coastal states are accorded sovereign rights to explore, exploit, and manage natural resources located in the water column and on the seabed within their EEZs. But their control of straddling stocks and highly migratory species while in their EEZs is subject to the provisions of the 1995 Fish Stocks Agreement, an arrangement treated as a legally binding implementing agreement under UNCLOS. Coastal states can designate portions of their EEZs as marine protected areas. Yet they have no authority to transfer portions of their EEZs into private hands, in contrast to the recognized authority of states to dispose of state-owned lands.

With regard to marine spaces located beyond the outer limits of EEZs, an area that still encompasses some $40-45 \%$ of the surface of the planet, a different set of constitutive provisions applies. In general terms, this area is not subject to ownership or control on the part of individual states. Unless otherwise determined, the high seas are not subject to claims of sovereignty and are open to use by all members of international society for peaceful purposes. These purposes include commercial navigation, fishing, overflight, and laying 
of subsea cables. The seabed beneath the high seas, known as the Area, is treated as having the status of the "common heritage of mankind." UNCLOS creates a body known as the International Seabed Authority to govern uses of the Area; Part XI of the convention establishes a fairly detailed governance system to guide the work of the authority. Beyond this, UNCLOS contains a variety of constitutive provisions that provide a basis for the development of specific regimes dealing with the protection of the marine environment.

The law of the sea is dynamic. The constitutive provisions set forth in UNCLOS differ in important respects from provisions relating to marine spaces prevailing as recently as the middle of the 20th century. And the system has continued to evolve since the completion of UNCLOS in 1982. Several implementing agreements negotiated during the 1990s are significant in constitutive terms. The current negotiations aimed at producing an implementing agreement dealing with issues of biodiversity beyond national jurisdiction may yield significant adjustments in constitutive provisions relating to marine genetic resources and obligations of states to produce environmental impact assessments. Nevertheless, UNCLOS continues to provide a constitutive arrangement governing human activities relating to marine spaces and resources. The collection of issue-specific regimes nested into this constitutive framework and dealing with a wide range of substantive issues has grown steadily.

What can we infer about effectiveness from this account of the constitutive arrangements that define international society? Many regard the institutions of the states system as ineffective because they impede or even block efforts to solve a variety of problems ranging from the proliferation of nuclear weapons to the eruption of pandemics and the onset of climate change. In effect, they see these arrangements as part of the problem rather than as a point of departure for creating effective governance systems. There is some justification for this argument. But it is important to recognize that this does not mean that these institutions are ineffective in constitutive terms. The constitutive features of international society clearly make a difference. Many believe that the single most important thing we need to do to address the challenges of planetary governance arising today is to alter these constitutive arrangements in fundamental ways. The result is a dramatic illustration of the difference between constitutive effectiveness and the issue-specific effectiveness we often have in mind when we speak of the effectiveness of international governance systems.

\section{ISSUE-SPECIFIC EFFECTIVENESS}

Although international society is hardly unique in these terms, the skeptics are right to emphasize the inability of states to create regimes to address a variety of specific needs for governance arising at the international level and the inad- 
equate performance of many issue-specific regimes that have been established to address particular problems. What is more, we are facing new challenges regarding matters like the eruption of pandemics and misuses of cyberspace that we are only beginning to recognize as prominent issues in world affairs. Nevertheless, some international regimes are effective in issue-specific terms, and there is much to be said for a careful assessment of success stories in the interests of thinking systematically about what works and why in the realm of Earth system governance. In this section, I consider in some detail the governance systems for Antarctica, the ozone layer, and the internet in order to clarify the idea of issue-specific effectiveness and to demonstrate that there are success stories in this realm.

The Antarctic Treaty of 1959, negotiated by 12 states during the midst of the Cold War, grew out of a desire to avoid serious disputes regarding jurisdictional claims in Antarctica and, more generally, a common interest in avoiding conflict regarding this uninhabited continent (Berkman et al. 2011). As the preambular language of the treaty puts it, "it is in the interest of all mankind that Antarctica shall continue forever to be used exclusively for peaceful purposes and shall not become the scene or object of international discord" (Antarctic Treaty 1959). In this connection, the treaty recognizes the "substantial contributions to scientific knowledge resulting from international cooperation in scientific investigation in Antarctica" and emphasizes the role of cooperation on "the basis of freedom of scientific investigation" as the cornerstone of a set of practices that will ensure that the continent is used exclusively for peaceful purposes.

The treaty then proceeds to set forth a set of prohibitions and requirements that form the core of this issue-specific international regime. Activities carried out under the provisions of the treaty can neither strengthen nor weaken preexisting jurisdictional claims relating to Antarctica. All military activities, including the establishment of military bases, the conduct of military maneuvers, and the testing of weapons, are prohibited. Nuclear explosions and the disposal of radioactive waste are prohibited. Contracting parties may designate observers, and all areas of Antarctica including all stations "shall be open at all times to inspection" on the part of these observers. The parties are required to transmit the reports of these observers to each other in conjunction with meetings of the Antarctic Treaty Consultative Parties. The contracting parties are required as well to provide each other with notice in advance regarding "all expeditions to and within Antarctica." If disputes arise, the parties are required to "consult among themselves with a view to having the dispute resolved" by peaceful means.

During the 60 years since the treaty entered into force in 1961, this regime has proven remarkably effective. The preexisting jurisdictional claims have largely withered away; the continent remains demilitarized, and scientific 
research in Antarctica continues to be robust. Additional contracting parties have joined the regime, and the parties have negotiated supplemental agreements, so that we now speak of the Antarctic Treaty System. Notable in this regard are the 1980 Convention on the Conservation of Antarctic Marine Living Resources, which sets up an innovative management system covering fishing and ecosystem management in the waters surrounding the continent, and the 1991 Protocol on Environmental Protection to the Antarctic Treaty, which contains a range of provisions designed to ensure environmental protection and prohibits "[a]ny activity relating to mineral resources, other than scientific research." No doubt, this regime may face significant challenges in the future, and it is plausible to argue that this is an easy case given the peripheral status of the continent and the low level of human activity occurring in the extreme conditions prevailing in Antarctica. Nevertheless, there is no denying that this regime, established to address an important need for governance under difficult conditions, has fulfilled its goals over time and proven sufficiently adaptable to remain resilient in the face of a range of significant changes in prevailing conditions over time.

The 1987 Montreal Protocol on Substances that Deplete the Ozone Layer, negotiated under the auspices of the United Nations, now has 197 members and is widely regarded as the most effective issue-specific environmental regime in existence (Andersen and Sarma 2002; Parson 2003). Nested within the framework provided by the 1985 Vienna Convention for the Protection of the Ozone Layer, the protocol provides an operational procedure for regulating and ultimately phasing out the production and consumption of chlorofluorocarbons, halons, and other substances that deplete the ozone layer. As scientific knowledge in this realm has advanced, the parties have adopted a series of amendments to the protocol accelerating phaseout schedules, adding more chemicals to the list of substances regulated under the terms of the protocol, and creating the Montreal Protocol Multilateral Fund to provide financial assistance to developing countries that need help in order to pursue development plans that avoid the use of ozone-depleting substances.

How should we evaluate the performance of this issue-specific regime? As a result of the phasing out of ozone-depleting substances, the health of the stratospheric ozone layer is improving, though there is some distance to go in restoring the ozone layer to its original condition. The interaction between scientists and policymakers in administering the regime and strengthening it in response to the growth of knowledge has worked well. As observers have noted, moreover, the Montreal Protocol has played a more important role in reducing emissions of greenhouse gases than the various components of the climate regime, including the 2015 Paris Climate Agreement (Velders et al. 2007). This is a consequence of the fact that many ozone-depleting substances are also greenhouse gases. Phasing out the production and consumption of these 
substances reduces emissions of greenhouse gases as a byproduct of restoring the ozone layer. A notable recent development is the Kigali Amendment, adopted at the 2016 Meeting of the Parties to the Montreal Protocol, which calls for phasing out the production and consumption of hydrofluorocarbons (HFCs), even though they are not ozone-depleting substances. At this writing, the ozone regime seems robust, and there is no reason to expect that its effectiveness will decline during the foreseeable future.

The issue-specific regime that has grown up to govern the internet differs fundamentally from the regimes for Antarctica and the ozone layer (DeNardis 2014). This regime is not based on an international legally binding instrument; its major provisions have arisen spontaneously and often through the initiatives of a range of nonstate actors. The regime features critical internet resources, including internet addresses, domain names, and transmission control protocols and internet protocols, which are drafted by the Internet Engineering Task Force and formalized by the Internet Architecture Board. These arrangements allow users to transmit data of various sorts from one device (e.g., a computer or a smart phone) to another virtually through the use of cyberspace. The regime does have some links to government agencies. For example, the Internet Corporation for Assigned Names and Numbers (ICANN) has a contractual link to the United States Department of Commerce, a situation that has given rise to some controversy and that is changing as a matter of fact if not in principle. But overall, the internet regime constitutes a prominent example of what some analysts have described as governance without government (Rosenau and Czempiel 1992).

The internet regime has performed well in the face of an explosion in the number of uses and users of cyberspace. Nevertheless, there are growing questions concerning the effectiveness of this regime going forward. Fundamentally, these questions arise from the rise of a variety of misuses of digital technologies, ranging from the harassment and bullying of individuals to invasions of privacy, identify theft, censorship using firewalls, interventions in electoral processes, and acts of espionage and terrorism. Taken together, these concerns pose profound challenges to the effectiveness of the governance system for the internet that has evolved more or less spontaneously over the last three decades. It is difficult to predict how the community will respond to these challenges in the coming years and whether the effectiveness of internet governance will suffer as a result. The internet has become far too integral to day-to-day life on a global basis to allow for any return to the status quo ante. Yet misuses of cyberspace have reached a point where it has become essential to take action to curb the worst offenses. There is little reason to expect that we can deal with this problem through the negotiation of one or more international legally binding instruments. States are among the worst offenders with regard to some of the most disruptive misuses of cyberspace (Perlroth 
2020). In any case, it is doubtful whether they have the resources to control a range of misuses in a politically acceptable manner. As a result, this problem now looms as a critical concern for all those interested in the effectiveness of issue-specific governance systems.

Can we draw any useful conclusions about issue-specific effectiveness from these success stories? One thing is clear: we cannot approach needs for governance in international society in a formulaic fashion, hoping that a more or less standard approach will suffice to deal with a variety of problems. The ozone regime features a multilateral environmental agreement, negotiated under the auspices of the United Nations, including virtually all members of international society as signatories, and administered as an activity of the UN Environment Programme. The Antarctic Treaty System encompasses a set of linked legally binding agreements not negotiated under the auspices of the United Nations and overseen by an independent secretariat supported informally by the Scientific Committee on Antarctic Research, which is formally a body of the International Science Council. The internet regime, by contrast, involves a set of practices that have evolved on an ad hoc basis, have no formal legal status, and provide opportunities for active engagement on the part of a variety of nonstate actors. All these arrangements work or have worked under specific conditions. Perhaps the principal lesson to be drawn from a consideration of these cases has to do with the issue of fit or, in other words, the importance of paying attention to compatibility between the major characteristics of a problem to be solved and the key features of the governance system developed to address it (Young 2002).

It seems fair to conclude from this account that the prospects for success are greatest when the problem is not regarded as critical to the core interests of the major players in the system. Unlike greenhouse gases like carbon dioxide, the production and consumption of ozone-depleting substances was not critical to the economic or political fortunes of any major actors. In 1987, the DuPont Corporation produced $\sim 25 \%$ of these substances. But the sale of the substances accounted for only $3 \%$ of DuPont's sales. The Antarctic Treaty was signed at the end of 1959 during an active phase of the Cold War. But the Soviet Union and the United States, neither of which had asserted jurisdictional claims relating to the continent, found themselves on the same side of the issue, wanting to neutralize the claims of the seven claimant states. The success of the 1957-1958 International Geophysical Year, which had included extensive scientific research in and on Antarctica, provided a convenient springboard for promoting the idea that the pursuit of knowledge could become the exemplary peaceful use of the continent. The one issue on the horizon today that could erode the resilience of the Antarctic Treaty System centers on the possibility that some members of the regime may become fixated on the search for and potential exploitation of minerals in Antarctica as an economic proposition. 
The informality and adaptability of the internet regime was an asset so long as the use of cyberspace was a relatively exotic activity of interest to a small number of people mostly engaged in science and the development of advanced technologies. What has transformed this regime into a matter of extreme economic and political sensitivity is the growth of the user community to include billions of people who rely on the internet to pursue their core interests or, in some cases, exploit it to harm the welfare of others. It is difficult to imagine, under the circumstances, a scenario under which the difficulties now plaguing this regime can be resolved through a series of adjustments in which the character of the regime remains unchanged.

All successful regimes must find ways to translate their principal provisions from paper to practice in a more or less systematic and sustained fashion. In analyses of the policy process, this is known as the issue of implementation. In the case of the ozone regime, implementation has not been particularly demanding. The UN Environment Programme has been able to monitor progress toward phasing out the production and consumption of a growing collection of chemicals. The multilateral fund has been able to achieve a lot with funding that is relatively modest by comparison with the funds needed to tackle other problems. For the most part, voluntary compliance has made it unnecessary to exercise the enforcement mechanism established under the terms of the Montreal Protocol. The key to the operationalization of the regime for Antarctica lies in the role of scientific organizations in the day-to-day administration of the regime's major provisions. Research is the principal human activity in Antarctica; science ministries or related bodies are responsible for funding and managing this activity, and interactions among the members of the science community interested in Antarctica are vigorous and generally cooperative. So far, the development of the internet regime has been a case of what we can think of as learning by doing. That is, there is no general blueprint for the regime (e.g., a treaty) requiring a specified set of activities to operationalize it. Various bodies, such as ICANN, the Internet Engineering Task Force, and the Internet Architecture Board, have been formed one by one as needs have arisen.

Another requirement for issue-specific effectiveness is the ability to adjust or adapt the provisions of a regime to changing circumstances in such a way as to strengthen rather than weaken its performance. A remarkable aspect of the performance of the ozone regime has been the ability of the Meeting of the Parties to make use of the amendment procedure provided for in the provisions of the protocol, not only to add the multilateral fund but also to expand the coverage of the regime from a few CFCs and halons to over 100 hazardous chemicals worldwide. There have been cases of noncompliance regarding the requirements of the regime. But they have not prevented steady progress toward fulfilling the goal of restoring the stratospheric ozone layer to its earlier 
condition. In the case of Antarctica, the key issue has been the balance of interests between those desiring to explore for valuable deposits of minerals on the continent and those dedicated to environmental protection. During the 1980s, the contracting parties devoted a great deal of time and energy to the negotiation of the 1988 Convention on the Regulation of Antarctic Mineral Resource Activities. When several key parties refused to ratify this convention, however, attention shifted sharply toward issues of environmental protection, resulting in the negotiation and entry into force of the environmental protocol to the Antarctic Treaty. While the protocol explicitly prohibits mineral exploration, this provides no guarantee that the issue will not surface again in the future. Much will depend on the course of the larger global debate regarding the future of industrialized societies and what we have come to think of as the green economy. When it comes to matters of adaptation, the situation of the internet regime is considerably more tumultuous. Many misuses of cyberspace involve efforts on the part of actors to exploit the capacity of the internet to pursue what are widely regarded as illegitimate purposes. There is every reason to expect that the resultant challenge will become more severe during the foreseeable future. Any effective response will undoubtedly require some combination of technological advances and the development of substantive norms. But the details of what such a response might look like are far from clear at this stage.

\section{POSITIONAL EFFECTIVENESS}

The phrase positional effectiveness may seem awkward to some. Many regard the fundamental concern in this realm as distributive in nature. To them, the issue is whether and how governance systems play a role in determining who gets what in interactions with one another. Clearly, this is a key issue. But the positional effects of institutions are not limited to their distributive consequences. Governance systems assign subjects to specific roles or to identifiable groups, shaping their identity and creating expectations about what constitutes appropriate behavior for occupants of these roles and members of these groups. Whether or not they make a difference in ordinary distributive terms, roles assign rights and duties to participants in social practices and shape norms governing the behavior of the occupants of various roles. In thinking about the positional effectiveness of governance systems, it seems desirable to cast a wide net to capture the full range of these effects.

At the constitutive level, prevailing international institutions divide the universe of actors cleanly into two non-overlapping categories: states and nonstate actors. From an institutional perspective, all states are the same, though in reality they differ drastically in terms of every other biophysical or socioeconomic criterion. All states enjoy sovereignty; all are eligible for membership in the United Nations; all may become signatories to international 
legally binding instruments; all are entitled to appear as parties to cases dealt with by the International Court of Justice. This institutional equality may prove beneficial to some actors in specific situations. For example, coalitions of small states can and often do join forces to pass resolutions in the UN General Assembly, even when a number of major powers are unwilling to join them or even oppose such initiatives openly. Similarly, requirements for entry into force incorporated in the texts of international conventions may make the willingness of small states to ratify more important than their activities regarding the issues at stake would suggest.

The phrase nonstate actors, by contrast, is a catchall encompassing everything from multinational corporations to nongovernmental organizations and intergovernmental organizations. What they have in common is simply that they are not states and are expected to abide by the rules prevailing in the states in which they are based. Powerful nonstate actors are not without influence in these terms. Corporations may have considerable bargaining strength in their dealings with governments, and they often demonstrate remarkable sophistication in their ability to take advantage of the provisions of differences among states with regard to tax systems and other financial arrangements. Intergovernmental bodies, like the United Nations bodies located in New York and Geneva, may operate under the terms of specialized agreements with host countries, including provisions regarding what is often described as extraterritoriality. But none of this alters the facts that nonstate actors do not enjoy the benefits associated with sovereignty and that they are expected to comply with the legal rules and regulations in force in the jurisdictions within which they operate.

International institutions produce distributive consequences in two distinct ways. For one thing, states vary dramatically in terms of the nature and extent of their natural capital and various types of social and human capital. The per capita income of advanced industrialized states is many times that of poor developing states; hundreds of millions of people in poor countries suffer from poverty, insecure food supplies, and a lack of health care. In other words, international society is characterized by extreme inequality, despite the fact that all its members are equal with regard to the rights, rules, and norms associated with statehood. And this inequality is baked into the system. That is, the prevailing institutional arrangements do not include any clear provisions obligating wealthy states to come to the assistance of poor states. Issues relating to foreign aid have been debated at length within international bodies like the organs of the United Nations, and some normative principles have emerged from these debates. Nevertheless, the contributions of individual states are voluntary, and some of the most wealthy and powerful states (e.g., the United States) have ignored international norms in this realm or imposed politically inspired restrictions on their willingness to help. 
Notable efforts to address this feature of the states system have emerged in the form of the Millennium Development Goals (MDGs) (2000-2015) and the Sustainable Development Goals (SDGs) (2016-2030). An interesting feature of these initiatives is that they highlight the idea of governing through goals in contrast to the more familiar rules-based governance (Kanie and Biermann 2017). The key idea here is that the members of international society working through the United Nations should reach agreement on the formulation of priority goals (e.g., ending poverty defined as living on less than $\$ 1.50$ a day) to be fulfilled within a specified period of time (e.g., 2000-2015) and then proceed to engage in a campaign to mobilize the effort needed to fulfill these goals (Sachs 2015). There is considerable debate regarding the results arising from this way of dealing with needs for governance. But the key point for purposes of this analysis is that experience with the MDGs and the SDGs does not reflect any important change in the inequality baked into the states system. While social pressure may play a role, states are not obligated to contribute in any specified way to the pursuit of these goals, and there is no prospect that these efforts will produce anything approaching equality at the level of international society, even if they do alleviate the suffering of some of the world's poorest people.

On the other hand, some institutional arrangements in international society produce distributive consequences precisely because they draw distinctions among the occupants of different roles or introduce provisions relating to benefit-sharing. Under the law of the sea, as it stands today, coastal states are entitled to enjoy the benefits they are able to derive from sizable marine areas known as EEZs, an entitlement that did not exist prior to the negotiation of the 1982 UN Convention on the Law of the Sea. The Area, by contrast, is characterized in the convention as the common heritage of mankind. The inclusion of provisions relating to benefit-sharing in conjunction with deep seabed mining in Part XI of UNCLOS dealing with the governance of the Area constitutes a major factor in the unwillingness of the United States to ratify the treaty. The UN Framework Convention on Climate Change, to take another example, introduces a distinction between Annex 1 and non-Annex 1 countries. Annex 1 countries are expected to take the lead in addressing the problem of climate change and to provide assistance to non-Annex 1 countries in devising development strategies that minimize emissions of greenhouse gases. This arrangement together with similar arrangements in other issue-specific regimes has given rise to the principle known as common but differentiated obligations. The basic idea is that it is appropriate to divide states into distinct categories in addressing needs for governance at the international level and to adopt different expectations regarding the contributions of those included in each category. Relative to the inequality baked into the states system, the significance of this principle is limited. Yet it does amount to a recognition that 
it is appropriate to divide the universe of states into subgroups for purposes of assigning responsibility for dealing with some specific needs for governance.

There is no doubt that international institutions produce positional effects. These effects may or may not correlate with issue-specific effectiveness and they may or may not produce results that are compatible with various normative principles regarding justice or fairness. Positional effectiveness in international society is particularly difficult to justify in terms of most approaches to what is generally known as distributive justice in contrast to procedural justice. This is an issue of obvious importance in today's world. But it does not detract from our understanding of the positional effectiveness of the institutional arrangements in place in international society. On the contrary, a major impediment to the achievement of outcomes that are more just or fair at the international level lies precisely in the positional effectiveness of the prevailing institutional arrangements.

I have discussed the constitutive, issue-specific, and positional effectiveness of social institutions as though they were separate phenomena. Up to a point, this makes sense. Institutions may be highly effective in constitutive terms, whether or not they provide a favorable point of departure for those seeking to address a specific need for governance, such as coming to terms with the emission of greenhouse gases. Similarly, institutions may be effective in positional terms, whether or not the results are compatible with addressing issue-specific concerns like the protection of biological diversity. For purposes of analysis, therefore, it seems reasonable to consider each dimension of effectiveness on its own terms.

Nevertheless, it is apparent that there are interaction effects between and among the individual dimensions of institutional effectiveness. Perhaps the most significant issue of this sort, mentioned at several points in the preceding sections, is that the defining institutional features of the states system may impede efforts to respond to issue-specific needs for governance like controlling the spread of nuclear weapons, addressing major humanitarian concerns, limiting emissions of greenhouse gases, or curbing misuses of cyberspace. This is a legitimate concern. The fundamental issue here centers on the institution of sovereignty, which immunizes states from outside interference in their internal affairs and allows states to refuse to abide by obligations they have not accepted freely. As the case of climate change makes clear, many actors are seeking to devise innovative ways to circumvent this problem. Thus, the pledge-and-review mechanism embedded in the 2015 Paris Climate Agreement allows states considerable leeway in formulating the terms of what are known as their Nationally Determined Contributions but also includes 
a procedure described as a "global stocktake" designed to exert pressure on member states to strengthen their commitments over time. In some ways, this is an ingenious effort to circumvent the limitations imposed by the constitutive arrangements of the states system. It is reasonable to suppose that ingenuity of this sort may work to produce solutions to some problems. But as numerous analysts have noted, the arrangements established under the terms of the Paris Climate Agreement seem inadequate to solve wicked problems like climate change.

This makes it relevant to ask whether mounting pressure to come to terms with such wicked problems will lead to significant changes in the constitutive provisions of the states system. It seems clear that the critical provisions are highly sticky, especially in a society that lacks well-developed mechanisms authorized to address issues of this sort. Still, it is worth reemphasizing the point made in an earlier section of this chapter regarding the fact that the states system as we know it today is an arrangement arising only in the period following the close of World War II. In other words, this system emerged as a result of the impact of forces operating within the lifetimes of people like myself. Given the intensity of the major biophysical and socioeconomic forces at work today, there is no reason to assume that the constitutive provisions of the system will remain unchanged during the course of the coming decades. This suggests that there is every reason to invest substantial time and energy in analyses of institutional dynamics regarding the constitutive provisions of the states system, including efforts to evaluate the relative merits of significant institutional options that may become feasible during the foreseeable future. I take up this topic more systematically in Chapter 8.

Another interaction effect centers on disconnects between issue-specific effectiveness and positional effectiveness. Existing international institutions are highly effective in assigning roles to states and nonstate actors, without reference to the consequences of doing so for efforts to address issue-specific problems. All states are regarded as equal in institutional terms, with limited exceptions like the designation of some states to play the role of permanent members of the UN Security Council in dealing with issues identified in Chapter VII of the Charter. Of course, we think a lot about power differentials among states, debating what we mean in using a term like hegemon, what it takes to be accepted as a great power, and what consequences the onset of the cyber age will have for the exercise of power at the international level. But all these are political calculations; they are not institutionalized in the constitutive provisions of the states systems.

One of the more interesting developments in the realm of planetary governance involves efforts to overcome such disconnects in the context of developing regimes to address specific problems. The creation of the multilateral fund as a component of the ozone regime, for example, reflects an explicit 
recognition of the need to provide assistance to developing states and is widely regarded as a key factor in accounting for the success of this regime. On the other hand, the case of climate change seems far less promising in these terms. The United States, for example, refused to ratify the Kyoto Protocol on emissions of greenhouse gas, arguing that its modest obligations were unfair despite the fact that the United States has one of the highest levels of per capita emissions in the world and is responsible for a large portion of historic emissions of the relevant gases. Similarly, some rich and powerful countries have encouraged polluting industries to move offshore, so that they can claim that they are taking steps to control emissions of greenhouse gases within their own jurisdictions. In such cases, effectiveness in dealing with issue-specific problems will certainly require a more substantial effort to come to terms with some of the positional consequences arising from the institutional provisions of the states system.

\section{A CONCLUDING THOUGHT}

Mainstream discussions of the effectiveness of governance systems are limited by a common failure to draw clear distinctions among what I have called constitutive, issue-specific, and positional effectiveness. In some respects, the institutional arrangements of international society are highly effective. They privilege the efforts of those seeking to maximize relative gains, impose constraints on efforts to solve collective-action problems, and entrench inequalities that limit the achievement of many elements of what we think of as sustainable development. This emphasizes the need to draw a clear distinction between the effectiveness of institutions in the general sense of making a difference and the ability of governance systems to solve specific problems like limiting the spread of nuclear weapons, controlling emissions of greenhouse gases, or curbing misuses of the internet. In fact, constitutive effectiveness can impede or even block the creation and implementation of regimes needed to solve issue-specific problems. This suggests that it will be essential going forward to find ways to modify the institutional arrangements of the states system. It would be naive to underestimate the magnitude of this challenge. Yet the states system as we know it today is a product of remarkably recent developments; there is no reason why we need to regard it as a monolithic institutional system whose continuation into the indefinite future must be accepted as a fact of life. 